\title{
Dietary intake of soybean protein and menstrual cycle length in pre-menopausal Singapore Chinese women
}

\author{
Rupert W Jakes ${ }^{1, *}$, t, Lynn Alexander ${ }^{2}$, Stephen W Duffy ${ }^{3}$, Joy Leong ${ }^{1}$, Lin Han Chen ${ }^{2}$ and \\ Wei Hong Lee ${ }^{2}$ \\ ${ }^{1}$ NMRC Clinical Trials \& Epidemiology Research Unit, Ministry of Health, 10 College Road, Singapore 169851, \\ Singapore: ${ }^{2}$ KK Hospital, 100 Bukit Timah Road, Singapore 229899, Singapore: ${ }^{3}$ MRC Biostatistics Unit, Institute \\ of Public Health, University Forvie Site, Cambridge CB2 2SR, UK
}

Submitted 7 March 2000: Accepted 12 July 2000

\begin{abstract}
Background: Intake of soybean protein was associated with a reduced risk of breast cancer in a case-control study. It has also been demonstrated to increase menstrual cycle length in an experimental setting.

Objective: To ascertain whether the association of soybean protein intakes with menstrual cycle length persists in an uncontrolled community setting.

Design: Cross-sectional food frequency dietary survey, menstrual cycle survey and prospective collection of menstrual cycle data.

Setting: A hospital clinic and a nursing college.

Subjects: Two hundred menstruating women.

Results: An association $(P=0.034)$ of higher intakes of soybean protein with increased menstrual cycle length, as recorded by self report and by prospectively recording three consecutive cycles, was observed. The risk of menstrual cycle length being greater than the median, when comparing the upper quartile (8.7$\left.35.2 \mathrm{~g} \mathrm{day}^{-1}\right)$ of soybean intake and the lowest quartile $\left(0.1-3.3 \mathrm{~g} \mathrm{day}^{-1}\right)$ was double, and this approached statistical significance $(\mathrm{OR}=2.02,95 \% \mathrm{CI}=0.88-4.64$ and $\mathrm{OR}=1.93,95 \% \mathrm{CI}=0.82-4.56$ for self-reported cycle length and cycle length as recorded by diary, respectively). In terms of the absolute association with cycle length, subjects in the upper quartile of soybean intake demonstrated a cycle length 1-2 days longer than did subjects in the lowest quartile.

Conclusions: It is likely that the association between dietary intake of soybean protein and length of menstrual cycle prevails in the community setting. This is shown using both self-reported cycle length and cycle length as recorded in a prospective diary.
\end{abstract}

\author{
Keywords \\ Phyto-oestrogens \\ Soybean protein \\ Menstrual cycle length \\ Breast cancer risk
}

Dietary intakes of different forms of protein, i.e. animal and plant, have been shown to affect breast cancer risk in retrospective and prospective studies ${ }^{1-5}$. The proportions of intake, as well as the total intake, of the different forms of protein, may have an effect on the overall risk of breast cancer. A high proportion of protein intake from soybean sources has been found to be associated with a significantly lower risk of breast cancer in a case-control study in Singapore ${ }^{1}$. In addition, a prospective study in Japan found a non-significant reduction in risk with daily consumption of soybean paste soup ${ }^{3}$. More recently, both

†Present address: Department of Public Health and Primary Care, Institute of Public Health, University Forvie Site, Cambridge CB2 2SR, UK. positive $^{6}$ and negative $e^{7,8}$ findings in relation to soybean intakes have resulted from epidemiological studies.

One proposed mechanism whereby the risk might be affected by soybean products is the replacement of relatively active endogenous oestrogens by inactive plant oestrogens, in which soybean protein is relatively rich $^{9}$. Thus, such foods may have an oestrogen suppressive effect. High intakes of soybean products have been shown to reduce oestrogen receptor concentrations in animal experiments ${ }^{9}$. Other animal studies have reported a higher incidence of mammary tumours in the presence of isoflavones ${ }^{10}$. In controlled experiments on human subjects, high soybean protein diets have been shown to increase menstrual cycle length and to bring about various hormonal changes ${ }^{11}$. A study conducted in 
Japan suggests intake of soybean milk can lower serum oestrogen levels ${ }^{13}$.

The effect of soybean protein in reducing breast cancer risk, with its possible hormonal mechanism, is of particular interest as it suggests a potential to unite the well established reproductive epidemiology with the often postulated, but still unclear, dietary aetiology. Here we report a study to assess whether the hormonal and ovulatory effects of variation in soybean protein intakes, observed in controlled experiments, are also observed in response to the variation in voluntary diet in the community at large. The motivation for this research is that the protective effect of soybean protein has the potential to explain, at least in part, the dramatic international variation in breast cancer incidence, with very high rates in western Europe and North America, and low rates in eastern Asia $^{14}$. If it is part of the hormonal aetiology of the disease, it should be active in the community as well as in controlled dietary experiments.

The pre-menopausal female population of Singapore, which has relatively high average intakes of soybean protein and reasonable variation around this average, was considered suitable for this study ${ }^{2}$. In this study we assessed soybean protein intakes in a survey sample of Singaporean women, and related these to menstrual cycle length and blood hormone concentrations.

\section{Methods}

\section{Subjects and eligibility}

The subjects were recruited as volunteers from two sources: a referral clinic at a local hospital $(n=85)$ and from a group studying for a nursing diploma at a polytechnic $(n=115)$. The subjects were attending the hospital clinic for a variety of reasons including general check-ups, pap-smears and fibroids. All subjects were screened before invitation to the study to confirm that they were menstruating regularly and did not have any condition that might affect their menstrual cycle or the level of sex hormones. Thirty of the eligible subjects approached from the hospital clinic refused consent, mainly for fear of pain from giving blood. Exclusions before invitation included current pregnancy, post-natal (3 months) or breast feeding, current oral contraceptive use, use of an intra-uterine device, hysterectomy, having significant medical or endocrine illness including pituitary, adrenal or thyroid disease. Following explanation of the study aims, signed consent was obtained.

It was intended to recruit the subjects from a common source, but the slow rate of accrual in the clinic setting prompted us to find an alternative source.

\section{Investigations}

Each subject responded to an interviewer-administered questionnaire that elicited intakes of soybean products, self-reported length and regularity of the menstrual cycle, age at menarche, number of pregnancies and births, use of exogenous hormonal drugs and time in days since last menstrual period. A semi-quantitative food-frequency questionnaire, previously validated for intakes of broad food groups and macronutrients, but not for soybean protein in particular, was used to assess dietary intake of soybean products ${ }^{1,2}$.

A blood sample was taken and analysed for concentrations of the following hormones: oestrone (E1), oestradiol (E2), oestriol (E3), luteinizing hormone (LH) and follicle stimulating hormone (FSH). E2 levels were measured on the Immulite analyser using the Immulite Estradiol kit. Intra-assay precision at a mean of 480 (SD 6.9) s.i. units has a CV of 6.3\%; inter-assay precision at a mean of 482 (SD 31) s.i. units has a CV of 6.4\%. E2 and E3 concentrations were measured using kits developed at the National University Hospital, Singapore. FSH and LH were measured on the Abbott's AxSYM using Abbott's diagnostic kits. For LH, intra-assay precision at a mean of 36.16 (SD 1.21) s.i. units has a CV of 3.3\%; inter-assay precision at a mean of 38.36 (SD 2.63) s.i. units has a CV of $6.7 \%$. For $\mathrm{FSH}$, intra-assay precision at a mean of 27.73 (SD 0.99) s.i. units has a CV of 3.6\%; inter-assay precision at a mean of 25.59 (SD 1.41) s.i. units has a CV of $5.7 \%$.

Diary charts were completed for three consecutive menstrual cycles following the interview, and returned to the investigators by post. Whether the subject was in follicular phase or luteal phase on the day of blood sample collection was calculated approximately, assuming ovulation was 14 days prior to the date of the start of the first cycle reported in the diary chart.

\section{Statistical considerations}

The results of Cassidy suggest that the mean difference between cycle length for a high intake of isoflavonic phyto-estrogens and that for a low intake would be 1.5 days, with a population standard deviation of around $2.2^{12}$. On this basis, for $80 \%$ power for a comparison of two such extreme groups, we would require 33 per group. We envisaged the consumption of soybean products between low and high intake groups in the Singapore population to be around $75 \%$ of that in the experimental situation, which would suggest a sample size of 64 per group, a total of 128 women $^{2}$. The actual regression analysis is likely to be more powerful than a dichotomization followed by a $t$-test, although noise introduced by dietary measurement is likely to counteract this. Further, previous studies using dietary instruments have experienced difficulties in compliance; it was estimated that as many as $25 \%$ of subjects would be unable to complete the interview. We therefore proposed a sample size of 200 women.

The association between the intake of soybean protein and cycle length was estimated first by simple correlation coefficients, then proportional odds modelling was used to take account of menstrual cycle length being ordered 
Table 1 Study group characteristics stratified by source of subjects

\begin{tabular}{lccccc}
\hline & \multicolumn{2}{c}{ Hospital clinic $(n=69)$} & & \multicolumn{2}{c}{ Nursing college $(n=115)$} \\
\cline { 2 - 3 } \cline { 5 - 5 } & Mean & SD & & Mean & SD \\
\hline Age (years) & 40.3 & 6.8 & & 26.8 & 11.0 \\
Age at menarche (years) & 13 & 1.5 & & 12 & 1.2 \\
Length of cycle (days) & & & & \\
$\quad$ Self-reported & 28 & 2.6 & & 29 & 7.8 \\
$\quad$ Diary & 29.2 & 4.8 & & 30.6 & 4.5 \\
Soybean protein (g day ${ }^{-1}$ ) & 5.4 & 4.5 & & 7.8 & 5.4 \\
\% Parous & 81 & 11.9 & & 6.2 & 6.6 \\
FSH (s.i. units) & 10.8 & 11.0 & & 7.5 & 9.9 \\
LH (s.i. units) & 9.4 & 216 & 550 & 314 \\
Oestrone (s.i. units) & 428 & 292 & & 309 & 341 \\
Oestradiol (s.i. units) & 321 & 0.17 & & 0.71 & 0.23 \\
Oestrone (s.i. units) & 0.63 & &
\end{tabular}

but discrete (measured to the nearest day), adjusting for age and subject source ${ }^{15}$. The potential association between soybean protein intakes and measured hormone levels was estimated using correlation coefficients, stratified by whether the blood sample was taken during the follicular or luteal phase of the menstrual cycle.

\section{Results}

Following completion of interviews nine subjects were excluded as a result of a clinical diagnosis that would affect a normal menstrual cycle (sub-fertility treatment, mid-cycle bleeding, dysmenorrhoea (four subjects), dysfunctional uterine bleeding, prolonged menses, and menorrhagia). Other exclusions included five subjects who were subsequently found to be receiving drug treatments that would affect levels of hormones (mercilon, norethisterone, danazol, oestriol and nordette), one schizophrenic subject, and one subject who had a hysterectomy soon after her interview. The remaining 184 subjects (69 from the hospital clinic and 115 from the nursing college) were included in all analyses; however, 12 subjects failed to return a complete menstrual diary chart and so could not be used in analyses where diary chart data were used as an endpoint.
Table 1 shows mean values and standard deviations for covariates separately for subjects from the hospital clinic and nursing college. The nursing college subjects are considerably younger than the clinic subjects and this is reflected in differences in cycle length and parity. The overall average soybean protein intake was 6.9 (SD 5.2) $\mathrm{g} \mathrm{day}^{-1}$ with absolute range $0.1-35.2 \mathrm{~g} \mathrm{day}^{-1}$ (lower quartile 3.3, median 5.7, and upper quartile 8.7). Mean levels of the measured hormones are also described in Table 1.

Table 2 shows the unadjusted effects of covariates on cycle length. A total soybean protein intake above the median ( $5.7 \mathrm{~g} \mathrm{day}^{-1}$ ) was significantly associated with a longer menstrual cycle length as measured in the diaries $(P=0.034)$. The test for trend with continuous values of intake was not significant $(P=0.16)$. For self-reported cycle length, soybean protein intakes above the median were associated with an increased risk of longer cycle length and this approached significance $(P=0.056)$. The trend in risk with continuous soybean protein intakes showed a similar result $(P=0.052)$.

The effect of soybean protein intake on cycle length as recorded in the diaries was slightly attenuated when adjusted for age $(\mathrm{OR}=1.81, P=0.07)$, subject source $(\mathrm{OR}=1.70, P=0.09)$ and parity $(\mathrm{OR}=1.73, P=0.08)$.

Table 2 Unadjusted effects on risk of having menstrual cycle length greater than the median, as estimated by odds ratios from logistic regression models

\begin{tabular}{|c|c|c|c|c|c|}
\hline & & \multicolumn{2}{|c|}{ Self-reported cycle length } & \multicolumn{2}{|c|}{ Average cycle length from diary } \\
\hline & & $n$ & OR $(95 \% \mathrm{Cl})$ & $n$ & OR $(95 \% \mathrm{Cl})$ \\
\hline Soybean protein $\left(\mathrm{g}\right.$ day $\left.^{-1}\right)$ & $\begin{array}{l}<5.7 \\
\geq 5.7\end{array}$ & $\begin{array}{l}92 \\
92\end{array}$ & $\begin{array}{l}1 \\
1.77(0.99-3.18)\end{array}$ & $\begin{array}{l}88 \\
84\end{array}$ & 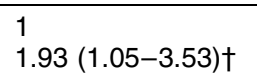 \\
\hline Subject source & $\begin{array}{l}\text { Hospital clinic } \\
\text { Nursing college }\end{array}$ & $\begin{array}{r}69 \\
115\end{array}$ & $\begin{array}{l}1 \\
1.70(0.93-3.11)\end{array}$ & $\begin{array}{r}64 \\
108\end{array}$ & $2.31(1.22-4.37) \dagger$ \\
\hline Age at menarche (years) & $\begin{array}{l}<13 \\
\geq 13\end{array}$ & $\begin{array}{l}98 \\
86\end{array}$ & $\begin{array}{l}1 \\
0.72(0.40-1.30)\end{array}$ & $\begin{array}{l}90 \\
82\end{array}$ & $0.62(0.34-1.14)$ \\
\hline Age (years) & & 184 & $0.95(0.93-0.98) \dagger$ & 172 & $0.94(0.91-0.96) \dagger$ \\
\hline Parous & $\begin{array}{l}\text { No } \\
\text { Yes }\end{array}$ & $\begin{array}{r}107 \\
77\end{array}$ & $\begin{array}{l}1 \\
0.56(0.31-1.02)\end{array}$ & $\begin{array}{r}102 \\
70\end{array}$ & $0.37(0.19-0.69) \dagger$ \\
\hline
\end{tabular}

\footnotetext{
${ }^{*}$ Age fitted as a continuous variable.
}

$+P<0.05$. 
Table 3 Odds ratios for length of cycle associated with quartiles of intakes of soybean protein

\begin{tabular}{|c|c|c|c|c|c|c|}
\hline \multirow[b]{2}{*}{ Intake of soybean protein (quartiles) $\left(\mathrm{g} \mathrm{day}^{-1}\right)$} & \multicolumn{3}{|c|}{ Self-reported cycle length } & \multicolumn{3}{|c|}{ Average cycle length from diary } \\
\hline & $n$ & Mean days & OR $(95 \% \mathrm{Cl})^{\star}$ & $n$ & Mean days & OR $(95 \% \mathrm{Cl})^{*}$ \\
\hline $\begin{array}{l}<3.3 \\
3.3-5.6 \\
5.7-8.6 \\
\geq 8.7 \\
\text { Linear test for trend }\end{array}$ & $\begin{array}{l}46 \\
46 \\
46 \\
46\end{array}$ & $\begin{array}{l}28.2 \\
27.3 \\
29.1 \\
30.8\end{array}$ & $\begin{array}{l}1 \\
1.09(0.48-2.52) \\
1.70(0.74-3.88) \\
2.02(0.88-4.64) \\
P=0.052\end{array}$ & $\begin{array}{l}44 \\
44 \\
42 \\
42\end{array}$ & $\begin{array}{l}29.7 \\
29.2 \\
30.7 \\
30.9\end{array}$ & $\begin{array}{l}1 \\
0.82(0.35-1.94) \\
1.59(0.68-3.73) \\
1.93(0.82-4.56) \\
P=0.16\end{array}$ \\
\hline
\end{tabular}

* Odds ratios for menstrual cycle length greater than the median, by logistic regression.

Adjusting for age in 5-year age categories ${ }^{16}$ and parity simultaneously, gave an OR for the effect of soybean protein intake of 1.84 (95\% CI $=0.97-3.50, P=0.06)$.

Similar results were observed using self-reported cycle length. Odds ratios, for length of cycle greater than the median, associated with quartiles of soybean intake showed a trend in the anticipated direction, but these did not reach statistical significance (Table 3). Again, adjusted for age in 5-year age groups and parity simultaneously produced an OR of $1.73(95 \% \mathrm{CI}=$ $0.88-3.37, P=0.1)$.

Table 4 shows correlation coefficients between hormone levels, cycle length, number of pregnancies and soybean protein intakes stratified by phase. There was a significant positive correlation between oestrone in the luteal phase and soybean protein intakes. Two subjects provided an insufficient volume of blood for a full hormone profile so do not feature in this matrix.

Correlation coefficients for non-hormonal outcomes are described in Table 5 and include all eligible subjects who returned the menstrual diary. A statistically significant correlation between soybean protein intake and selfreported length of cycle was found. Self-reported cycle length also correlated well with cycle length as collected by the diaries.

\section{Discussion}

Soybean protein intakes have been observed to reduce the incidence of mammary tumours in animals ${ }^{9}$. Soybean protein is rich in isoflavonic phyto-oestrogens ${ }^{12}$, and has been observed to increase menstrual cycle length in controlled human experiments ${ }^{11}$. In addition, high soybean protein intakes were associated with reduced risk of human breast cancer in a case-control study in Singapore ${ }^{1}$.

Two caveats should be borne in mind with respect to the results. First, the effects on menstrual cycle of soybean protein intakes are not invariably and unequivocally significant. They should therefore be regarded as strongly suggestive rather than definitive. Secondly, the absolute size of the effect is modest. The results do, however, at

Table 4 Correlation matrix for measured hormones, cycle length, pregnancies and soybean protein intake, stratified by phase of cycle

\begin{tabular}{|c|c|c|c|c|c|c|c|c|c|}
\hline & E1 & E2 & E3 & $\mathrm{FSH}$ & $\mathrm{LH}$ & Cycle* & Cycle† & Pregnancy & Soybean \\
\hline \multicolumn{10}{|l|}{ Luteal $(n=80)$} \\
\hline Oestrone (E1) & 1 & & & & & & & & \\
\hline Oestradiol (E2) & $0.5346 \ddagger$ & 1 & & & & & & & \\
\hline Oestriol (E3) & $0.4449 \ddagger$ & 0.1575 & 1 & & & & & & \\
\hline $\mathrm{FSH}$ & 0.1755 & 0.0147 & -0.0213 & 1 & & & & & \\
\hline LH & $0.3979 \ddagger$ & $0.5081 \ddagger$ & $0.2305 \ddagger$ & $0.4586 \ddagger$ & 1 & & & & \\
\hline Cycle length* & -0.0466 & -0.0419 & 0.0387 & -0.1654 & 0.0563 & 1 & & & \\
\hline Cycle length $†$ & -0.0480 & -0.2041 & -0.0190 & 0.0856 & 0.0983 & $0.4772 \ddagger$ & 1 & & \\
\hline No. pregnancies & $0.2485 \ddagger$ & 0.1356 & 0.1936 & $0.2978 \ddagger$ & 0.0853 & -0.0935 & -0.1866 & 1 & \\
\hline Soybean protein & $0.2221 \ddagger$ & -0.0326 & 0.0667 & 0.0526 & -0.0262 & 0.1848 & 0.0521 & -0.0074 & 1 \\
\hline \multicolumn{10}{|l|}{ Follicular $(n=90)$} \\
\hline Oestrone (E1) & 1 & & & & & & & & \\
\hline Oestradiol (E2) & $0.6796 \ddagger$ & 1 & & & & & & & \\
\hline Oestriol (E3) & $0.2437 \ddagger$ & 0.0149 & 1 & & & & & & \\
\hline $\mathrm{FSH}$ & -0.0975 & -0.1379 & -0.1069 & 1 & & & & & \\
\hline $\mathrm{LH}$ & -0.0103 & 0.0329 & -0.1730 & $0.6500 \ddagger$ & 1 & & & & \\
\hline Cycle length* & -0.1786 & -0.1519 & -0.0436 & -0.1711 & -0.1267 & 1 & & & \\
\hline Cycle length† & 0.0254 & -0.0840 & -0.1819 & 0.0738 & 0.0431 & $0.6155 \ddagger$ & 1 & & \\
\hline No. pregnancies & -0.0794 & 0.0245 & 0.1280 & 0.1249 & 0.1186 & -0.0125 & -0.1588 & 1 & \\
\hline Soybean protein & 0.0853 & -0.0403 & 0.1985 & 0.0143 & 0.0422 & 0.1653 & 0.1437 & -0.1730 & 1 \\
\hline
\end{tabular}

FSH, follicle stimulating hormone; LH, luteinizing hormone.

* Self-reported cycle length.

† Cycle length from diary cards.

$\ddagger P<0.05$ 
Table 5 Correlation matrix for cycle length, pregnancies and soybean protein intake $(n=172)$

\begin{tabular}{lcccc}
\hline & Cycle length & Cycle length $\dagger$ & No. pregnancies & Soybean protein \\
\hline Cycle length $^{\star}$ & 1 & 1 & & \\
Cycle length $\dagger$ & $0.5613 \ddagger$ & $-0.1706 \ddagger$ & 1 & \\
No. pregnancies & -0.0461 & 0.0949 & -0.0941 & 1 \\
Soybean protein & $0.1728 \ddagger$ & & \\
\hline
\end{tabular}

* Self-reported cycle length.

† Cycle length from diary cards.

$\ddagger P<0.05$.

least support, complementary to the experimental evidence, that high intakes of soybean protein can influence the menstrual cycle at community level.

The phyto-oestrogens in soybean protein are weak oestrogens, and their effect in animals is likely to be antioestrogenic $^{17}$. There is also evidence, approaching statistical significance, that soybean milk lowers serum oestrogen levels in human subjects ${ }^{13}$, although this was not observed in our study. This is consistent with increased menstrual cycle length as a result of high intakes and this increase has been demonstrated in experiments on human subjects ${ }^{11}$. Our results lend support to the evidence that variation in soybean protein intakes at a community level correlates with menstrual cycle length and with serum oestrone levels.

Although the reporting of results stratified by phase of cycle was not a primary endpoint, it should be acknowledged that using time to next cycle to determine whether the blood sample was taken in the follicular or luteal phase is a very approximate method. Also, some of the women may have been sampled during anovulatory cycles. With a more exact method of calculating phase, our secondary results, correlations with hormone levels might have been more statistically significant, particularly with respect to the luteal phase. The study population comprised subjects drawn from two sources. However, the major difference was that of age and adjustment for age had little effect on the results.

If we translate a modest increase in cycle length of 1.2 days between the lower and upper quartiles of soybean intake as shown in these data, using cycle length recorded by diary, the effect over a lifetime is approximately 20 fewer cycles. At a mean cycle length of 30.9 days this equates to 2 fewer years of menstruating life for those in the upper quartile of soybean intake.

A reduction in lifetime ovarian activity has been related to reduced breast cancer risk $^{18}$. Other studies have demonstrated a reduced risk of breast cancer with high soybean protein intakes ${ }^{1}$. Our results suggest that dietary intake of soybean protein lengthens menstrual cycle length, possibly through a biological mechanism that modifies ovarian activity. This may have important implications for the modification of breast cancer risk through dietary interventions.

\section{Acknowledgements}

This study was supported by Grant NMRC/0253/1997 from the National Medical Research Council, Singapore.

\section{References}

1 Lee HP, Gourley L, Duffy SW, Esteve J, Lee J, Day NE. Dietary effects on breast-cancer risk in Singapore. Lancet 1991; 337: $1197-200$

2 Lee HP, Gourley L, Duffy SW, Esteve J, Lee J, Day NE. Risk factors for breast cancer by age and menopausal status: a case-control study in Singapore. Cancer Causes and Control 1992; 3: 313-22.

3 Hirayama T. Lifestyle and mortality. Basel: Karger, 1990.

4 Nomura AMY, Henderson BE, Lee J. Breast cancer and diet among the Japanese in Hawaii. Am. J. Clin. Nutr. 1978; 31 : 2020-5.

5 Vatten LJ, Solvoll K, Loken EB. Frequency of meat and fish intake and risk of breast cancer in a prospective study of 14,500 Norwegian women. Int. J. Cancer 1990; 46: 12-5.

6 Hirose K, Tajima K, Hamajima N, Inoue M, Takezaki T, Kuroishi T, et al. A large-scale, hospital-based case-control study of risk factors of breast cancer according to menopausal status. Jpn. J. Cancer Res. 1995; 86(2): 146-54.

7 Yuan JM, Wang QS, Ross RK, Henderson BE, Yu MC. Diet and breast cancer in Shanghai and Tianjin. China. Br. J. Cancer 1995; 71(6): 1353-8.

8 Key TJ, Sharp GB, Appleby PN, Beral V, Goodman MT, Soda $\mathrm{M}$, et al. Soya foods and breast cancer risk: a prospective study in Hiroshima and Nagasaki. Japan. Br. J. Cancer 1999; 81(7): $1248-56$.

9 Barnes S, Grubbs C, Setchell KDR, Carlson J. Soybeans inhibit mammary tumours in models of breast cancer. In: Pariza MW, ed. Mutagens and Carcinogens in the Diet. New York: Wiley-Liss, 1990: 239-53.

10 Hsieh CY, Santell RC, Haslam SZ, Helferich WG. Estrogenic effects of genistein on the growth of estrogen receptorpositive human breast cancer (MCF-7) cells in vitro and in vivo. Cancer Res. 1998; 58: 3833-8.

11 Cassidy A, Bingham S, Setchell KDR. Biological effects of a diet of soy protein rich in isoflavones on the menstrual cycle of premenopausal women. Am. J. Clin. Nutr. 1994; 60: 33340.

12 Cassidy A, Bingham S, Setchell KDR. Biological effects of isoflavones in young women - importance of the chemical composition of soy products. Br. J. Nutr. 1995; 74: 587-601.

13 Nagata C, Takatsuka N, Inaba S, Kawakami N, Hiroyuki S. Effect of soymilk consumption on serum estrogen concentrations in premenopausal Japanese women. J. Natl. Cancer Inst. 1998; 90(23): 1830-5.

14 Parkin DM, Muir CS, Whelan SL, Gao YT, Ferlay J, Powell J. 
Cancer Incidence in Five Continents. Lyon: International Agency for Research on Cancer, 1992.

15 McCullagh P. Regression models for ordinal data. J. R. Stat. Soc. B 1980; 42: 109-27.

16 Cooper GS, Sandler DP, Whelan EA, Smith KR. Association of physical and behavioral characteristics with menstrual cycle patterns in women aged 29-31 years. Epidemiology 1996; 7(6): 624-8.

17 Setchell KDR, Aldercreutz H. Mammalian ligands and phyto-oestrogens: recent studies on their formation, metabolism and biological role in health and disease. In: Rowland IR, ed. Role of the Gut Flora in Toxicity and Cancer. New York: Academic Press, 1988: 315-45.

18 Andrieu N, Smith T, Duffy S, Zaridze DG, Renaud R, Rohan T, et al. The effects of interaction between familial and reproductive factors on breast cancer risk: a combined analysis of seven case-control studies. Br. J. Cancer 1998; 77(9): 1525-36. 